\title{
Effects of hydrophilic surface treatment on evaporation heat transfer at the outside wall of horizontal tubes
}

\author{
H.-Y. Kim ${ }^{\text {a }}$, B.H. Kang ${ }^{\text {b,* }}$ \\ ${ }^{a}$ ThermallFlow Control Research Center, Korea Institute of Science and Technology, \\ Seoul 136-791, South Korea \\ ${ }^{\mathrm{b}}$ School of Mechanical and Automotive Engineering, Kookmin University, Seoul 136-702, South Korea
}

Received 24 May 2002; accepted 28 October 2002

\begin{abstract}
An experimental study has been conducted to investigate the effects of hydrophilic surface treatment on evaporation heat transfer at the outside wall of various kinds of copper tubes. Plain, spiral, corrugated, and low-finned tubes were selected as test tubes. In this work, to increase the wettability of distilled water on copper tubes, a novel hydrophilic surface treatment method using plasma was employed. The experiments show that every kind of hydrophilic surface treated tube tested in the work exhibits superior evaporation heat transfer performance as compared with that of the same kind of untreated tube. It is found out that during the evaporation process, the high wettability of the surface obtained through hydrophilic treatment induces film flow on the tubes while sessile drops are formed on untreated tubes. The film has a smaller thickness as well as a greater heat transfer area than the sessile drops, and this yields higher heat transfer rate for hydrophilic surface treated tubes than that for untreated tubes.
\end{abstract}

(C) 2002 Elsevier Science Ltd. All rights reserved.

Keywords: Evaporation heat transfer; Hydrophilic surface treatment; Wettability

\section{Introduction}

The operations of most thermal systems involve heat transfer between fluids, and many types of heat exchangers are used to enhance the heat transfer efficiency. Currently, demands for an absorption refrigerator are rapidly increasing with much interest in protecting natural environments. In the main components of the absorption system including an evaporator and an absorber, a

\footnotetext{
* Corresponding author. Tel.: +82-2-910-4681; fax: +82-2-910-4839.

E-mail address: bhkang@kookmin.ac.kr (B.H. Kang).
} 
shell-and-tube heat exchanger is generally used for its relatively low pressure drop in the system [1]. However, since the size of absorption system is larger than that of vapor-compression system, to enhance the efficiency of the absorption system is critically required for the reduction of its size. So far, to promote the heat transfer in heat exchangers of the system, either the heat transfer area of the tubes has been increased by mechanical modification or the thermal boundary-layer thickness has been reduced by hydrophilic coating of the tube surface using surfactants.

Many results are available of enhanced evaporation heat transfer on mechanically modified tubes [2,3]. For example, Fletcher et al. [2] obtained the evaporation heat transfer coefficient 2.5 times higher than that of plain tubes by grooving the outside wall of the plain tubes. In addition, Kim [3] showed that the evaporation heat transfer of thin liquid film on horizontal low-finned tubes is $60-100 \%$ more efficient than that on plain tubes. When a surfactant is used to enhance heat transfer, the coated surfactant is dissolved in refrigerant as it flows down the outside wall of tubes although the surfactant coating initially improves the heat transfer performance. This dissolution of the surfactant hampers the wide use of the surfactant-coating method since it deteriorates hydrophilic property of the surface as the time elapses and it may also cause environmental problems.

Recently, a novel hydrophilic surface treatment method which overcomes such problems of the conventional surfactants has been developed [4,5]. In this surface treatment technology, a metal specimen whose surface needs treating is placed in a vacuum chamber, and a polymer gas and a reactive gas are supplied into the chamber at a relatively low vacuum state (lower than $0.1 \mathrm{~Pa}$ ). Then electric potential difference is induced at two ends of the specimen to give rise to DC or RF discharge, which generates plasma that forms a hydrophilic polymer layer on the surface. The polymer layer is so hydrophilic that the receding contact angle of water on the surface is less than $30^{\circ}$. This hydrophilic property results from its high surface energy due to such radicals as $\mathrm{C}-\mathrm{N}$, $\mathrm{C}-\mathrm{O}$, and $\mathrm{N}-\mathrm{H}$ residing on the surface. Therefore, this technology can maintain the hydrophilic property longer and more stably than the aforementioned surfactant-coating method. Ha et al. [6] experimentally verified the superior quality of the surface treated by this method in a condensation process. In their experiments on the condensation of water vapor and its drainage in a fin-tube exchanger, the surface treated by the plasma method was shown to have a higher heattransfer coefficient as well as to sustain its property longer than a surface coated by a surfactant.

In this work, the effects of the hydrophilic surface treatment on the "evaporation" heat transfer at the outside wall of horizontal tubes are experimentally investigated. The plain and modified tubes, such as spiral, corrugated and low-finned tubes are tested here and the measurement results before and after hydrophilic treatment are compared. The test is made in an experimental setup simulating an evaporator of an absorption refrigerator. The evaporation heat transfer characteristics of the tubes are studied as varying the evaporator inlet temperature, the internal flow rate, and the evaporation pressure of the test chamber.

\section{Experimental apparatus and methods}

An experimental setup, which simulates an evaporator where the actual cooling takes place in an absorption refrigerator, was fabricated for this study. Fig. 1 shows a schematic diagram of the setup. The test chamber consists of an evaporator section and a condenser section. Nozzles in the 


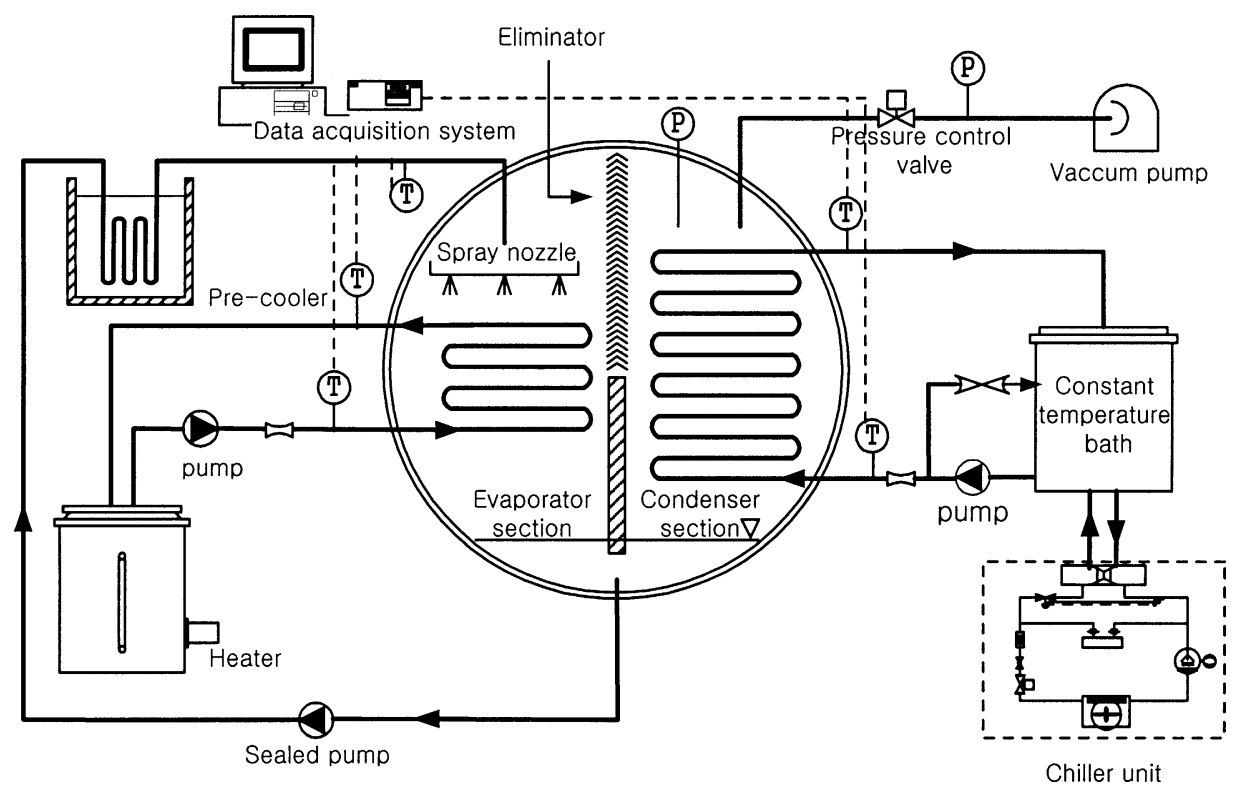

Fig. 1. Experimental setup.

evaporator section uniformly spray the refrigerant (distilled water in this case) over the evaporator surface. The refrigerant evaporates on the outside wall of the evaporator tube surface and its vapor is collected on the condenser surface. A vacuum pump is employed to provide the initial operating pressure in the chamber.

A constant-temperature bath with an electrical heater of the $3 \mathrm{~kW}$ capacity supplies the evaporator with hot water, whose temperature is higher than the evaporation temperature of the test chamber, via a circulation pump. The flow rate of hot water is measured by a flowmeter whose measurement range is $0.18-0.96 \mathrm{~m}^{3} / \mathrm{h}$. The hot water is cooled by evaporation of refrigerant at the outside wall of the evaporator tubes and returns to the bath to be re-circulated.

Another constant-temperature bath is used to supply the condenser with cooling water at a constant temperature. Water in the bath is cooled by a chiller with the capacity of $11.6 \mathrm{~kW}(3 \mathrm{RT})$. The cooled water first passes a flowmeter and enters a condenser tube to subtract heat from vapor generated in the evaporator. Water thus heated returns to the bath to be cooled again.

Three spraying nozzles, $120 \mathrm{~mm}$ apart from each other, are situated $150 \mathrm{~mm}$ above the evaporator tubes to ensure a uniform distribution of refrigerant. The spray was observed through a view port on the chamber. The refrigerant that evaporates on the outside wall of the evaporator tubes enters the condenser section through an eliminator. Condensed refrigerant collected at the bottom of the test chamber is re-circulated to the spray nozzles by a pump. Since the temperature of the refrigerant rises while passing the pump, a pre-cooler between the pump outlet and the nozzle inlet is used to keep the nozzle inlet temperature constant.

T-type thermocouples measure the inlet and outlet temperature of both the evaporator and the condenser and the inlet temperature of the nozzles. The error in the difference between the inlet and outlet temperature is evaluated to be $\pm 0.2^{\circ} \mathrm{C}$. 
Table 1

Experimental conditions

\begin{tabular}{lll}
\hline & Inlet temperature $\left({ }^{\circ} \mathrm{C}\right)$ & Flow rate $\left(\mathrm{m}^{3} / \mathrm{s}\right) \times 10^{5}$ \\
\hline Condenser & $15 \pm 0.5$ & 6.5 \\
Evaporator & $40,50,60$ & $1.50-8.7$ \\
Nozzle & $20 \pm 0.5$ & 0.4 \\
\hline
\end{tabular}

Experimental conditions used in this study are shown in Table 1. It takes approximately $20 \mathrm{~min}$ for the conditions to reach a steady state from the beginning of each run. Experimental data are recorded for $5 \mathrm{~min}$ by a data acquisition system (Yokogawa DR230) connected to a digital computer.

Fig. 2 shows various types of tubes that are used in this study. As modified tubes, spiral, corrugated and low-finned tubes are selected for their wide use in industry. Table 2 shows specifications of each test tube. The outer diameters of untouched sections of all the modified tubes are $12.7 \mathrm{~mm}$. A low-finned tube has $26 \mathrm{fpi}$ (fins per inch), and the fin height is $1 \mathrm{~mm}$. The evaporator tubes are bundled in such a form that three rows of the tube are connected in series and each row is $400 \mathrm{~mm}$ long. The hydrophilic surface tubes are prepared using the condition that is known to induce the best hydrophilic property on their surfaces. Refrigerant is supplied from nozzles onto straight sections only. Therefore, U-shaped connections between each straight section of the tubes do not participate in the evaporation heat transfer.

The condenser was made of a 3 by 5 array of $400 \mathrm{~mm}$ copper tubes with outer diameter of 12.7 $\mathrm{mm}$ to allow a large surface area. Thus obtained surface area was five times larger than the

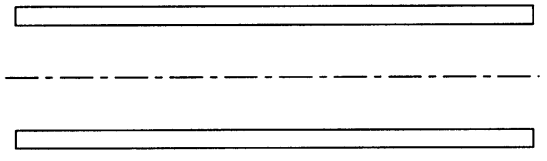

(a)

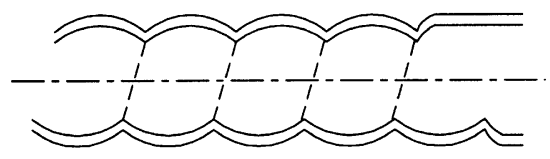

(c)

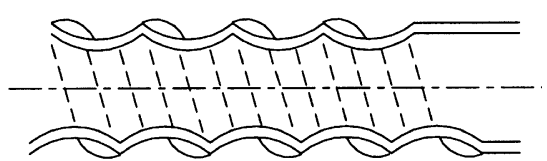

(b)

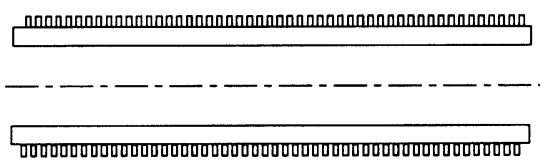

(d)

Fig. 2. Schematics of the test tubes: (a) plain tube, (b) spiral tube, (c) corrugated tube and (d) low-finned tube.

Table 2

Dimensions of the test tubes

\begin{tabular}{lllll}
\hline Type & Outer diameter $(\mathrm{mm})$ & Inner diameter $(\mathrm{mm})$ & Wall thickness $(\mathrm{mm})$ & Groove pitch $(\mathrm{mm})$ \\
\hline Plain & 12.7 & 11.5 & 0.6 & 6.2 \\
Spiral & 12.7 & 7 & 0.6 & 6.4 \\
Corrugated & 12.7 & 10.2 & 0.6 & $26 \mathrm{fpi}$ \\
Low-finned & 12.7 & 8.5 & 1.1 & \\
\hline
\end{tabular}


evaporator's heat transfer area, so that a nearly complete condensation of the refrigerant vapor was ensured.

\section{Experimental results and discussions}

\subsection{Analysis of the experimental results}

The rate of heat transferred from the evaporator, $Q$, is calculated as

$$
Q=\dot{m} C\left(T_{\text {in }}-T_{\text {out }}\right),
$$

where $\dot{m}$ denotes the internal flow rate of the evaporator, $C$ is the heat capacity of the liquid, and $T_{\text {in }}$ and $T_{\text {out }}$ are the inlet and outlet temperature of the evaporator, respectively. $U A$, the product of the total heat transfer coefficient, $U$, and the heat transfer area, $A$, is obtained as the following:

$$
U A=\frac{Q}{\Delta T_{\mathrm{lm}}} .
$$

Here $\Delta T_{\mathrm{lm}}$ is the log mean temperature difference (LMTD), which is calculated as:

$$
\Delta T_{\mathrm{lm}}=\frac{\left(T_{\text {in }}-T_{\text {out }}\right)}{\ln \left[\left(T_{\text {in }}-T_{\text {sat }}\right) /\left(T_{\text {out }}-T_{\text {sat }}\right)\right]},
$$

where $T_{\text {sat }}$ is the saturation temperature. Here we choose the saturation temperature as a representative temperature of the refrigerant. Our preliminary experiments show that the effect of the sensible heat resulting from the subcooling of the refrigerant is negligible compared with the latent heat transfer. The Reynolds number, $R e$, is defined as:

$$
R e=\frac{\rho d_{\mathrm{i}} V}{\mu},
$$

where $\rho$ is the density of water, $d_{\mathrm{i}}$ the inner diameter of a tube, $V$ the average internal flow velocity, and $\mu$ the viscosity. When calculating the mean flow rate and the Reynolds number of the internal flow in both the corrugated tube and the spiral tube, an average value of the inner diameter was used considering the variation of the inner diameter of those tubes. Using the above relations, experimental results of the evaporation heat transfer at the outside wall of various tubes are presented below.

\subsection{Experimental results}

Fig. 3(a) shows the effects of the Reynolds number inside the evaporator tube on the evaporation heat transfer rate per unit surface area, $q$. In the experiments, the evaporation pressure and the water temperature entering the evaporator tube were maintained at $4.25 \mathrm{kPa}$ (corresponding evaporation temperature being $30{ }^{\circ} \mathrm{C}$ ) and $50{ }^{\circ} \mathrm{C}$, respectively. In the figure, HPT denotes the hydrophilic-treated tube. As the Reynolds number increases, the evaporation heat transfer rate increases as expected. In the entire Reynolds number range, it is shown that the mechanically modified tubes result in higher heat transfer rate than the plain tube. In addition, the evaporation 

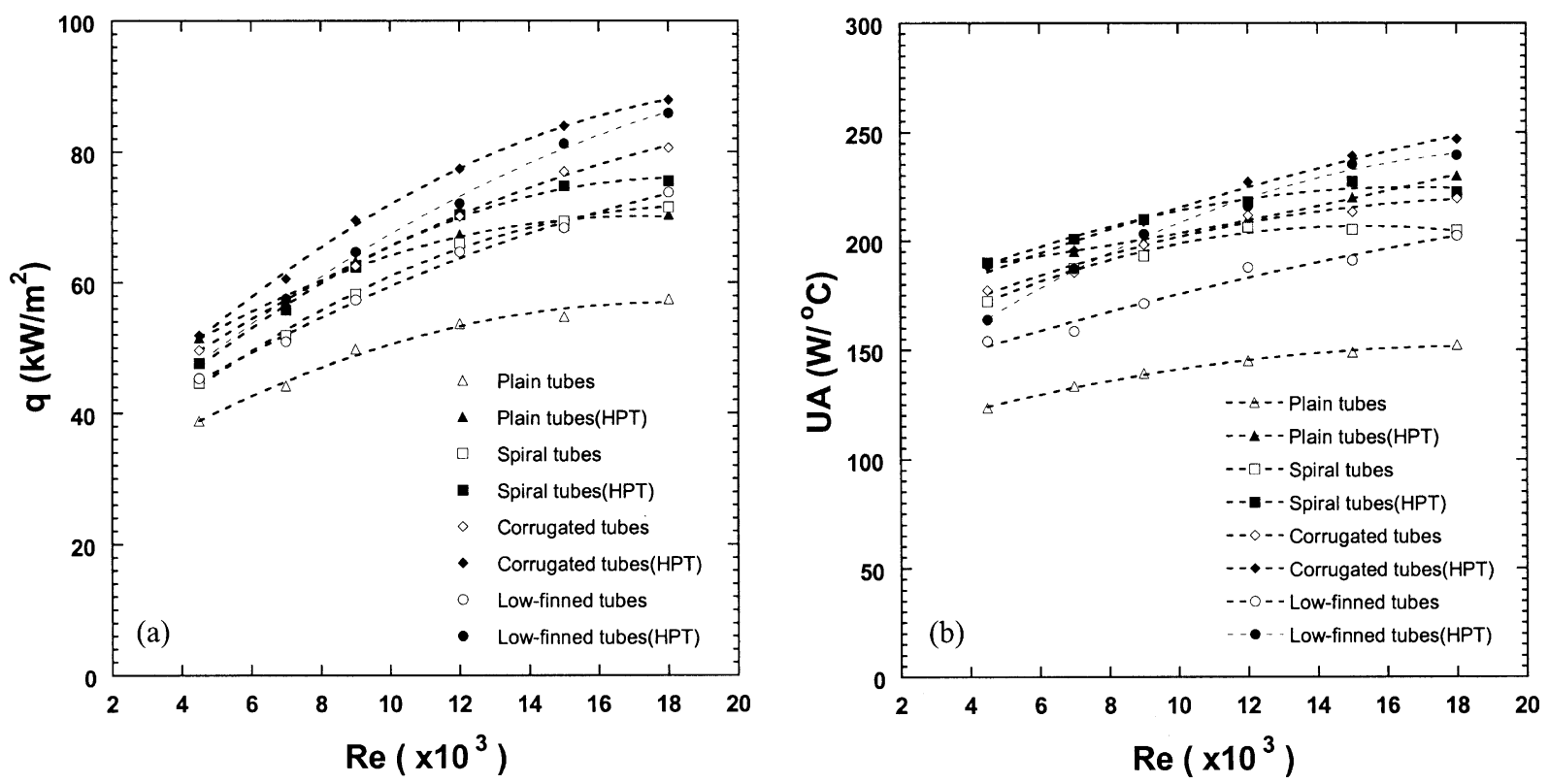

Fig. 3. Experimental results of the evaporation heat transfer while varying the water mass flow rate $(R e)$ into evaporator. (a) The heat transfer rate per unit surface area vs. Re and (b) $U A$ vs. $R e$.

heat transfer on the hydrophilic-treated tubes is greater than that on untreated ones for all kinds of tubes. Among the mechanically modified tubes, the corrugated tubes generally exhibit superior heat transfer performance to the other tubes in both surface treated and untreated state.

The effects of the Reynolds number, i.e. the mass flow rate in the evaporator tube, on the $U A$ values are shown in Fig. 3(b). In the entire range of Re, the $U A$ values gradually increase as Re increases. When the tubes were surface-treated, the $U A$ values were enhanced by $40-77 \%$ for a plain tube, $6-11 \%$ for a spiral tube, $5-12 \%$ for a corrugated tube, and $7-23 \%$ for a low-finned tube.

In other experiments that investigate effects of other parameters than $R e$, the internal flow rates were set at $R e=15,000$ for all the kinds of tubes. Fig. 4(a) shows the effects of the evaporator inlet temperature on the heat transfer rate while the evaporation pressure in the test chamber is maintained at $4.25 \mathrm{kPa}$. As the inlet temperature increases from 40 to $60^{\circ} \mathrm{C}$, the evaporation heat transfer rate increases as well. The hydrophilic surface treatment enhanced the heat transfer rate of a plain tube by $27-54 \%$, of a spiral tube by approximately $10 \%$, of a corrugated tube by 10 $24 \%$, and of a low-finned tube by 10-23\%. Fig. 4(b) shows the effects of the evaporator inlet temperature on the $U A$ value instead of the heat transfer rate. Contrary to a trend observed in Fig. 4(a), the $U A$ values decrease as the evaporator inlet temperature increases. This can be understood by considering that the Prandtl number of water decreases as its temperature increases. Since the heat transfer coefficient decreases as the Prandtl number decreases in general, the increase in the water temperature results in the decrease in the $U A$ values. Therefore, the increase in the evaporation heat transfer rate in spite of the water inlet temperature increase indicates that the decrease in the $U A$ values is fully compensated by the increased temperature difference between the hot water and the evaporating liquid. The $U A$ values of the surface-treated tubes are higher than 

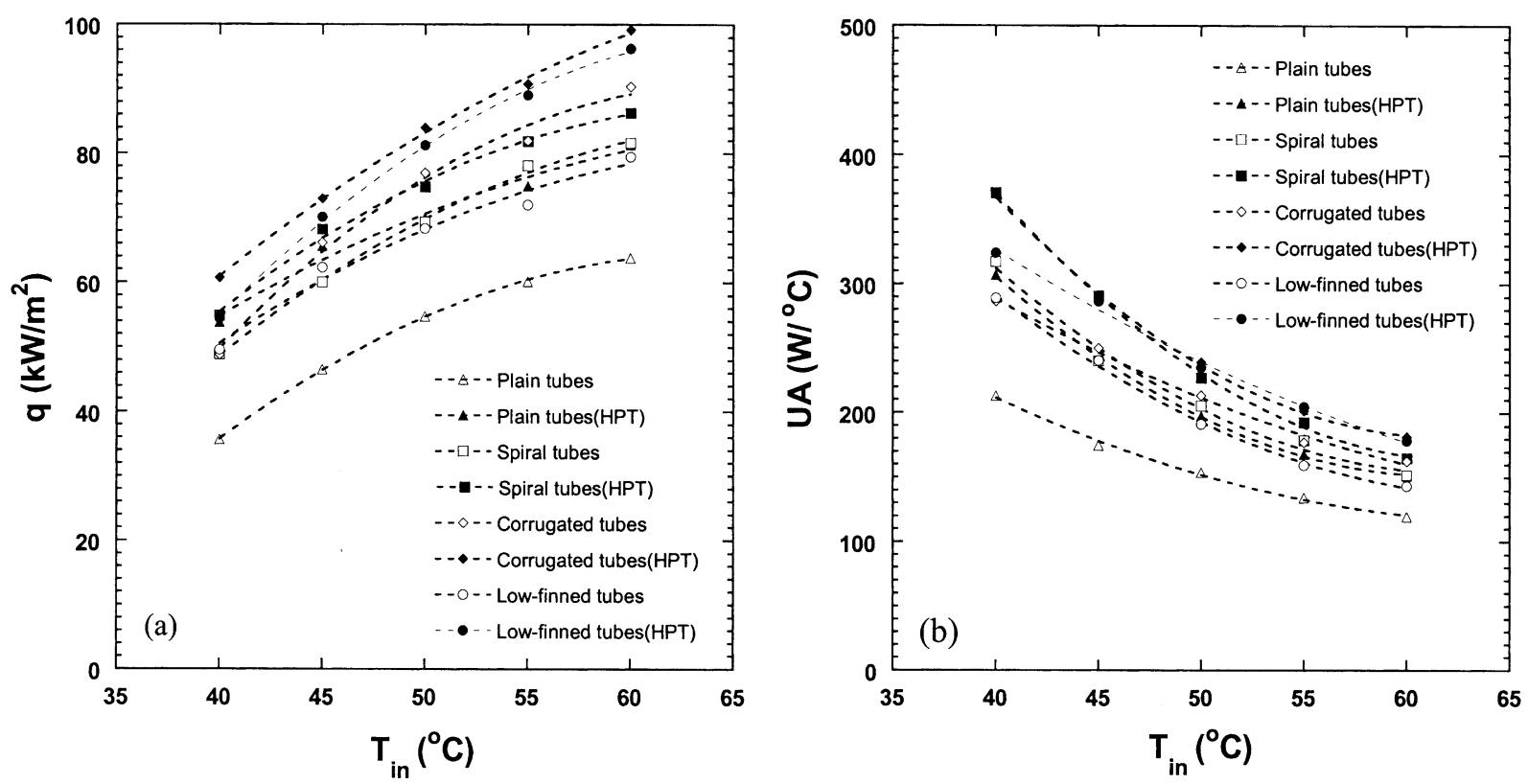

Fig. 4. Experimental results of the evaporation heat transfer while varying the evaporator inlet temperature. (a) The heat transfer rate per unit surface area vs. $T_{\text {in }}$. (b) $U A$ vs. $T_{\text {in }}$.

untreated tubes by $36-45 \%$ for a plain tube, $8-21 \%$ for a spiral tube, $12-29 \%$ for a corrugated tube, and $12-28 \%$ for a low-finned tube.

The effects of the evaporation pressure in the test chamber on the heat transfer rate are shown in Fig. 5(a). In the experiments, the inlet temperature of the nozzles and that of water entering the evaporator are maintained at 20 and $50^{\circ} \mathrm{C}$, respectively. The pressure in the test chamber is varied as $2.34,4.25$ and $7.38 \mathrm{kPa}$, and the corresponding evaporation temperature is 20,30 and $40{ }^{\circ} \mathrm{C}$, respectively. The experimental results suggest that as the evaporation pressure increases, the heat transfer rate slightly decreases. This trend results from the fact that the difference between the evaporator inlet temperature and the evaporation temperature decreases as the chamber pressure increases. Fig. 5(b) shows the effects of the evaporation heat transfer on the $U A$ values. As the evaporation pressure increases, the $U A$ values increase contrary to the tendency of the heat transfer rate. This can be understood by examining the sensitivity of $U A$ to the variation of the saturation pressure, or equivalently $T_{\text {sat }}$. Since Fig. 5(a) indicates that $q_{e}$ varies with the saturation pressure only slightly, the dependency of $U A$ on $T_{\text {sat }}$ can be estimated using $\partial(U A) / \partial T_{\text {sat }}$, and its sign merely follows that of $\left(T_{\text {in }}-T_{\text {out }}\right)$ which is always positive. After surface-treating the tubes, the $U A$ values were enhanced by approximately $40 \%$ for a plain tube, $5-27 \%$ for a spiral tube, $5-12 \%$ for a corrugated tube, and $19-26 \%$ for a low-finned tube.

\subsection{Mechanism of heat transfer enhancement}

The difference of the evaporation heat transfer rate at the outside wall of horizontal tubes is mainly caused by the difference in the configuration of the liquid flow covering the tubes. Fig. 6 

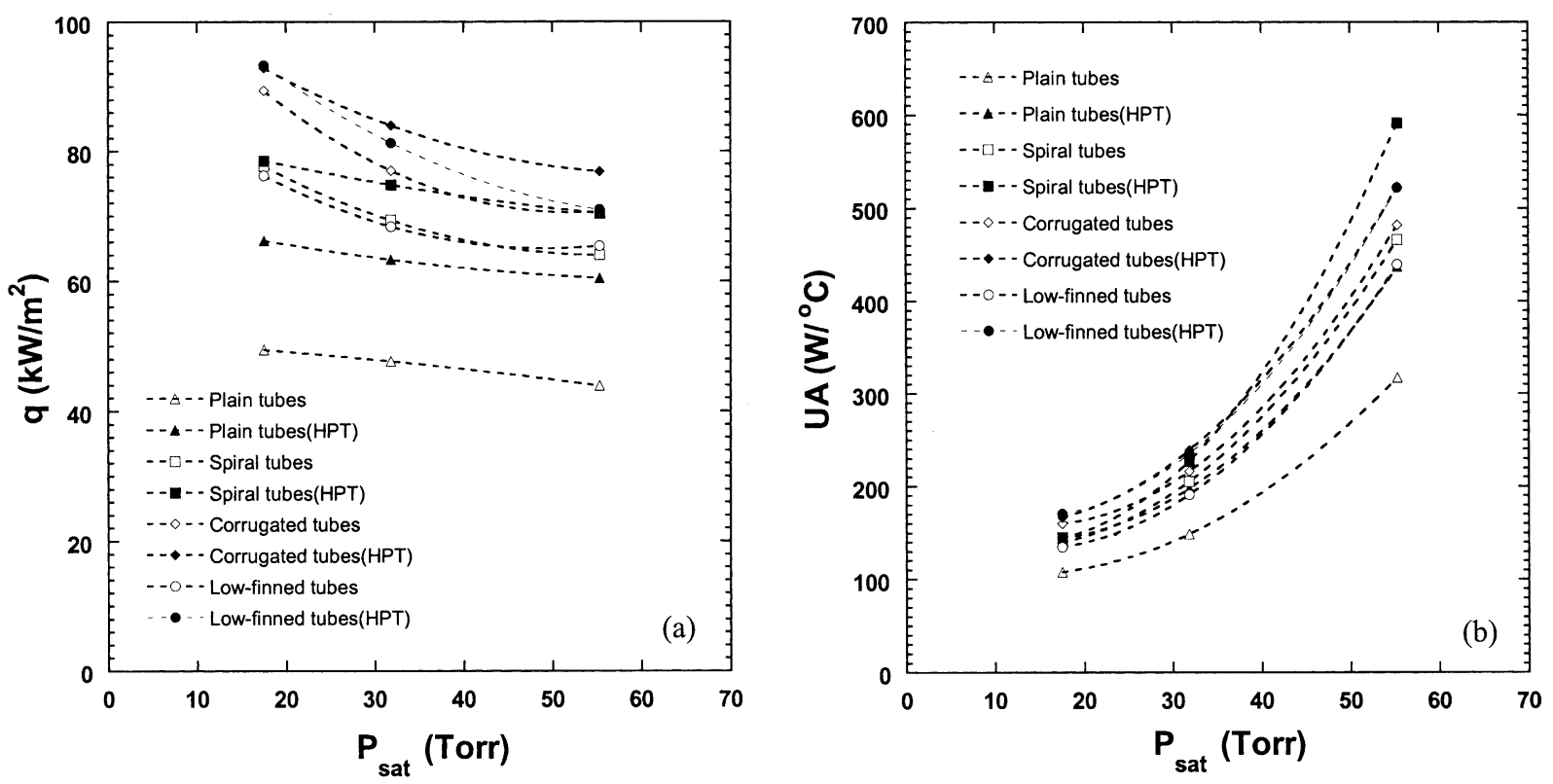

Fig. 5. Experimental results of the evaporation heat transfer while varying the saturation pressure. (a) The heat transfer rate per unit surface area vs. $P_{\text {sat }}$ (b) $U A$ vs. $P_{\text {sat }}$.

compares the configuration of the liquid forming on plain tubes before and after hydrophilic treatment. The liquid on the untreated tube forms discrete sessile drops due to nonwetting surface properties between water and the tube, but the liquid on the hydrophilic treated tube drains as a thin film. A similar difference is observed for mechanically modified tube as well. The experimental results presented in this work suggest that the evaporation heat transfer is promoted when the liquid flows as a film (on hydrophilic treated tubes) rather than when it forms discrete drops (on untreated tubes).

Here it is noted that when vapor condenses on subcooled surface, dropwise condensation results in higher heat transfer performance than film condensation [7,8]. During dropwise condensation, very small droplets are nucleated and most of heat is transferred via these droplets. When the droplets grow large enough by continuous condensation and coalescence with adjacent droplets, they slide down the surface under gravity, sweeping the surface clean of droplets. Tiny droplets grow a new on the fresh surface, repeatedly providing a heat transfer path of very low thermal resistance. Namely, the characteristic features of dropwise condensation that very small droplets are formed on the surface and that a fresh surface keeps being exposed make it a more preferable mode of condensation [8].

However, in the evaporation heat transfer phenomena investigated here, relatively large drops are introduced from the spray onto the surface, rather than by spontaneous nucleation of vapor as in the condensation process. Thus the foregoing heat transfer mechanism of dropwise condensation does not apply to this case. Those large drops introduced from the spray sit on a nonwetting tube for a certain time while providing a heat transfer path having relatively high thermal resistance, until they leave the surface due to disturbance of other drops sprayed from the nozzle near themselves. 


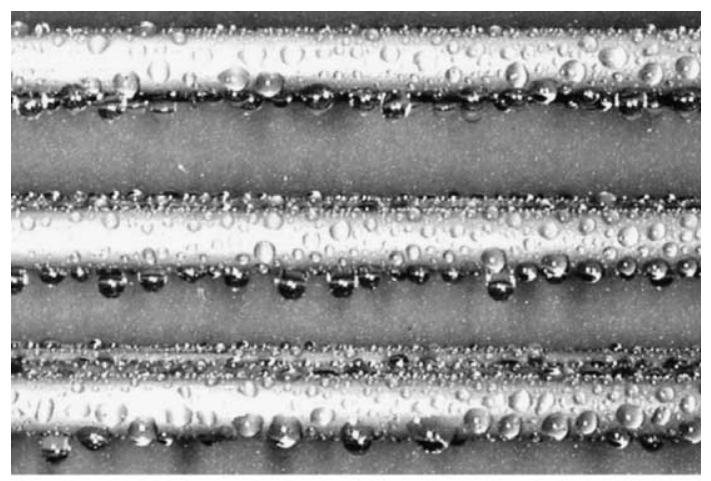

(a)

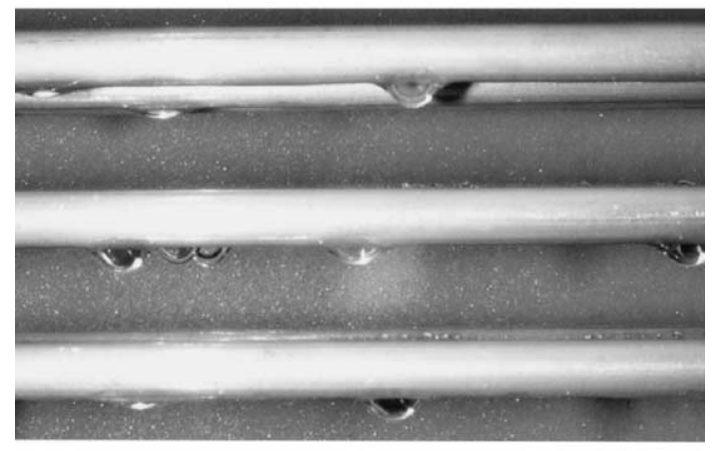

(b)

Fig. 6. Comparison of liquid configurations flowing over (a) untreated tube surface and (b) hydrophilic treated tube surface.

On the other hand, liquid drops sprayed onto hydrophilic tube surface spread to a great extent and merge with adjacent drops to form a thin film draining down the tube. The film is very thin and the resultant thermal resistance is fairly low. Based on the experimental conditions used in this work (tube outer diameter of $12.7 \mathrm{~mm}$ and the mass flow rate from the nozzle of $4 \mathrm{mg} / \mathrm{s}$ which is distributed equally on three tube sections), the film thickness can be approximated. Assuming fully developed flow and negligible thickness change along the tube surface, the film thickness is estimated to be about $100 \mu \mathrm{m}$. This value is much smaller than the average size of drops appearing in Fig. 6(a), which is of the order of millimeters. Consequently, it can be said that the superior heat transfer performance of the hydrophilic tubes results from the fact that the liquid films on hydrophilic treated tubes have smaller thickness and touches wider surface area than discrete drops on untreated tubes. Therefore, to promote the evaporation heat transfer at the outside wall of horizontal tubes while supplying liquid externally, forming thin films on the tube surface is preferable to keeping the liquid on tube as drops. It is this argument that has been empirically verified in the experimental results above.

Lastly, investigating the above results reveals that the plain tube exhibits greater improvements in evaporation heat transfer when hydrophilic treated than the modified tubes. It is speculated to be because the modified tubes already experience the effects of increased heat transfer area even before hydrophilic treatment. Therefore, the impact of the hydrophilic treatment on the 
evaporation heat transfer of modified tubes is not as pronounced as that on the heat transfer of plain tubes.

\section{Conclusions}

This study experimentally investigated the effects of the hydrophilic surface treatment using plasma on the evaporation heat transfer of various tubes. The experiments show that hydrophilic treated tubes of all the kinds tested exhibit superior evaporation heat transfer performance as compared with those untreated. Therefore, the hydrophilic coating of evaporator tubes using plasma seems to be a viable method for improving the efficiency of many thermal systems including absorption refrigerators. The underlying mechanism that enhances the evaporation heat transfer in this work is that the hydrophilic treatment induces film flow rather than sessile drops onto tube surface. The film has a smaller thickness and a greater heat transfer area than sessile drops, which results in improved heat transfer rate.

\section{References}

[1] S.C. Lee, Shell-and-tube heat exchangers for air-conditioning and refrigeration system, Korean J. Air-Conditioning Refrig. Eng. 27 (1998) 209-217.

[2] L.S. Fletcher, V. Sernas, W.H. Parken, Evaporation heat transfer coefficients for thin sear water films on horizontal tubes, Industrial Eng. Chem., Process Des. Develop. 14 (1975) 411-416.

[3] N.H. Kim, Enhancement of thin film evaporation on low-fin tubes, Korean J. Air-Conditioning Refrig. Eng. 10 (1998) 674-682.

[4] S.K. Koh, K.H. Kim, W.K. Choi, S.C. Choi, S.C. Ha, Wettability hydrophilic surface formation by ion assisted reaction, Proceedings of the International Conference and Exhibit, Heat Exchangers for Sustainable Development, Lisbon, Portugal, 1998, pp. 593-612.

[5] J.S. Cho, Y.-W. Baeg, S. Han, K.-H. Kim, J. Cho, S.-K. Koh, Hydrophilic surface formation on materials and its application, Surface Coatings Tech. 128 (2000) 66-70.

[6] S.C. Ha, C.H. Kim, S.P. Ahn, G.A. Dreitser, Condensate drainage characteristics of plate fin-and-tube heat exchanger, Proceedings of the International Conference and Exhibit, Heat Exchangers for Sustainable Development, Lisbon, Portugal, 1998, pp. 423-430.

[7] A.F. Mills, Heat Transfer, first ed., Irwin, Homewood, Illinois, 1992, p. 596.

[8] V.P. Carey, in: Liquid-Vapor Phase-Change Phenomena, Hemisphere, Washington DC, 1992, p. 343. 